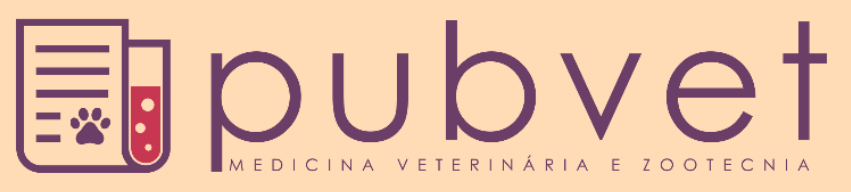

https://doi.org/10.31533/pubvet.v12n10a187.1-5

\title{
Exodontia pela técnica intraoral em égua: Relato de caso
}

\author{
Filipe Fernandes de Morais $^{1}{ }^{\bullet}$ Andressa Sampaio da Silveira ${ }^{2} \bullet$, Fernando Antônio \\ Pinto $^{1}$, Lucilo Bioni da Fonseca Filho ${ }^{1} \bullet$, Lourival Barros de Sousa Brito Pereira ${ }^{3} \bullet$, Júlio \\ Cézar dos Santos Nascimento ${ }^{4}{ }^{\bullet}$, Jordy Diniz de Oliveira Lima ${ }^{1}$, Gabriella Mignac \\ Mendonça Wanderley ${ }^{\circ}{ }^{\circ}$, Giovanna Isabella de Souza Couto ${ }^{6}{ }^{\circ}$, Hélio Lauro Soares \\ Vasco Neto $^{7}$ ๑
}

${ }^{I}$ Médico veterinário. Recife-PE Brasil.

${ }^{2}$ Discente do curso de zootecnia em Universidade Federal Paraíba, Patos-PB.

${ }^{3}$ Médico Veterinário, Recife-PE Brasil. E-mail: lorinho2013.1@hotmail.com *Autor para correspondência

${ }^{4}$ Professor em Universidade Federal Rural de Pernambuco. Recife-PE Brasil. E-mail: juliozootecnista@hotmail.com

${ }_{5}^{5}$ Discente do curso de Medicina Veterinária em Centro Universitário Mauricio de Nassau. Recife-PE Brasil.

${ }^{6}$ Discente do curso de Medicina Veterinária em Universidade Federal Rural de Pernambuco. Recife-PE Brasil.

${ }^{7}$ Professor em Centro Universitário Mauricio de Nassau. Recife-PE Brasil.

RESUMO. Alterações dentárias, ao decorrer dos anos, devido ao processo de domesticação e confinamento dos equinos, associado à falta de um manejo correto e tratamento odontológico periódico precário, dentre outros requisitos, aparecem com frequência, levando o animal a alguns problemas intra-orais. Algumas afecções na rotina veterinária tornam-se comuns na grande maioria dos haras, por falta de uma avaliação antecipada sem que o mesmo apresente algum tipo de incômodo ou queda no seu desempenho. Isto ocorre principalmente, quando se trata de um animal atleta. Contudo, a importância do cuidado na rotina dos haras com a cavidade oral dos equinos, para uma boa mastigação e deglutição do alimento, torna-se de extrema relevância, evitando danos maiores futuros. O processo de avaliação veterinária deve ser de intensa solicitação por parte do tutor, para poder proporcionar uma boa qualidade de vida ao animal. Pontas dentárias, por exemplo, causam traumas na mucosa, resultando em uma série de incômodos tanto para o animal, quanto para o seu dono. Objetivou-se nesse trabalho relatar o caso de exodontia do elemento 307. Neste, existia uma infecção bacteriana causada por um canal interligando uma fístula na região mandibular com o meio intra-oral. Foram realizados bloqueios anestésicos através do forame mandibular e metoniano com bupivacaína, associado à infusão com sedativo com detomidina. A falta do tratamento da doença periodontal dessa égua resultou na enfermidade apical, causando também halitose, redução do seu escore corporal. Concluiu-se ainda mais que, um bom tratamento odontológico dos equinos torna-se de suma necessidade para seu desenvolvimento atleta, alimentar e de seu bem-estar, levando assim também uma vida prolongada e saudável do animal.

Palavras chave: clínica veterinária, doença apical, equinos, odontologia

\section{Exodontia by intraoral technique in mare: Case report}

ABSTRACT. Dental changes, over the years, due to the process of domestication and confinement of the equines, associated to the lack of a correct management and precarious periodic dental treatment, among other requirements, appear frequently, leading the animal to some intraoral problems. Some conditions in the veterinary routine become common in the vast majority of farms, due to the lack of an early evaluation without it presenting some kind of discomfort or a fall in their performance. This occurs mainly when it comes to an animal athlete. However, the importance of routine care of horse farms with the oral cavity of horses for good chewing and swallowing of food becomes extremely relevant, avoiding 
future major damage. The veterinary evaluation process must be intensively requested by the tutor, in order to provide a good quality of life for the animal. Dental tips, for example, cause trauma to the mucosa, resulting in a number of discomforts for both the animal and its owner. The objective of this study was to report the case of element 307 exodontia. In this, there was a bacterial infection caused by a canal interconnecting a fistula in the mandibular region with the intraoral environment. Anesthetic blocks were performed through the mandibular and metonian foramen with bupivacaine, associated with the sedative infusion with detomidine. The lack of treatment of the periodontal disease of this mare resulted in the apical disease, also causing halitosis, reduction of its corporal score. It was further concluded that a good dental treatment of the equines becomes of great necessity for its athlete development, food and its well-being, thus also leading a prolonged life healthy of the animal.

Keywords: veterinary clinic, apical desease, horses, odontology

\section{Exodoncia por la técnica intraoral en yegua: Reporte de un caso}

RESUMEN. Los cambios en los dientes, a lo largo de los años, debido al proceso de domesticación y confinamiento de los equinos, asociado a la falta de un manejo correcto y tratamiento odontológico periódico precario, entre otros requisitos, aparecen con frecuencia, llevando al animal a algunos problemas intraorales. Algunas afecciones en la rutina veterinaria se vuelven comunes en la gran mayoría de los haras, por falta de una evaluación anticipada sin que el mismo presente algún tipo de incomodidad a caída en su desempeño. Esto ocurre principalmente cuando se trata de un animal atleta. Sin embargo, la importancia del cuidado en la rutina de los haras con la cavidad oral de los equinos, para una buena masticación y deglución del alimento, se vuelve de extrema relevancia, evitando daños mayores futuros. El proceso de evaluación veterinaria debe ser de intensa solicitud por parte del tutor, para poder proporcionar una buena calidad de vida al animal. Las puntas dentales, por ejemplo, causan traumas en la mucosa, resultando en una serie de incómodas tanto para el animal, como para su dueño. Se objetivó en ese trabajo relatar el caso de exodoncia del elemento 307. En éste, existía una infección bacteriana causada por un canal interconectando una fístula en la región mandibular con el medio intraoral. Se realizaron bloqueos anestésicos a través del foramen mandibular y metoniano con bupivacaína, asociado a la infusión con sedante con detomidina. La falta del tratamiento de la enfermedad periodontal de esa yegua resultó en la enfermedad apical, causando también halitosis, reducción de su escore corporal. Se concluyó aún más que un buen tratamiento odontológico de los equinos se vuelve de suma necesidad para su desarrollo atleta, alimentario y de su bienestar, llevando así también una vida prolongada sana del animal.

Palabras clave: clínica veterinária, enfermedad apical, equinos, odontologia

\section{Introdução}

O cavalo moderno (Equus caballus) teve sua evolução a partir do gênero Hyracotherium que se caracterizava por ser um animal braquidonte, visto que não apresentava coroa de reserva em seus elementos dentários. Com o decorrer do tempo e da evolução, devido a algumas mudanças climáticas, as vegetações sofreram várias alterações levando o animal a ter uma mastigação de mais atrito e mais lenta. Por esse motivo, mudanças aconteceram nos elementos dentários, tais como o aumento do tamanho do dente com o surgimento de uma coroa de reserva (dentes hipsodontes), como também o tempo que levará para a erupção (Easley et al., 2010). Nos antecedentes dos Equus caballus, estudos constam que os mesmos passavam em torno de 3-4 horas por dia alimentando-se, onde a dieta era baseada em vegetais ricos em proteínas que eram facilmente digeríveis. Hoje, diante das mudanças o cavalo atual requer um tempo em média de 16 horas diárias para suprir o valor energético necessário para sua mantença e execução de atividades, que por sua vez necessita de uma quantidade maior de alimento (Kreling, 2003).

A dieta dos equinos sofreu grandes alterações devido à mudança do manejo, confinamento e domesticação onde, o concentrado com o valor 
energético altíssimo (peletizado) passou a ser fornecido com maior frequência e assim, os animais mudaram consideravelmente o tempo de ingestão e o movimento de mastigação, levando a ter uma apresentação mais vertical do que lateral. O conteúdo mastigado ligado a outros fatores como: período de mastigação, estrutura dentária e a presença de processos dolorosos. Uma vez que corroboram para o maior ou menor desgaste dos dentes, pelo atrito e intensidade entre as duas faces oclusais. O processo pode dar início a alguns problemas dentários que por sua vez, se não intervindos no tempo correto, podem levar a outros danos desagradáveis (ex: doenças periodontais, ulcerações, lesões vestibulares, etc.) (Dixon \& Dacre, 2005). Os animais afetados podem demostrar um menor desempenho atlético e dificuldade na manutenção do seu escore corporal por apresentar dificuldade no ato de alimentar-se por conta do processo doloroso na mastigação, fazendo com que o mesmo não se alimente devidamente predispondo a problemas futuros (Dixon et al., 2006).

\section{Relato do caso}

Foi realizado o atendimento de uma égua num haras localizado na cidade de Gravatá, região do agreste Pernambucano. O tutor e o tratador do animal relataram que desde três meses atrás o mesmo apresentava sinas de incômodo, halitose intensa, lesão no lado esquerdo da mandíbula com presença de secreção purulenta, aparentes dores ao mastigar, redução no consumo de alimento e consequentemente queda gradativa do seu escore corporal. Também informaram a aplicação de analgésico (Dipirona - D500) e administração de cicatrizantes na ferida da mandíbula sem a prescrição do veterinário já que não era comum a prevenção ou assistência veterinária na propriedade.

Durante o exame físico constatou-se a fístula localizada no lado esquerdo da mandíbula com presença de secreção purulenta (Figura 1). Ao avaliar a cavidade oral do animal, constatou-se halitose intensa, ganchos craniais no $2^{\circ}$ pré-molar (Figura 3A), lesões na região vestibular da bochecha, pontas excessivas de esmalte dentário, cárie infundibular no elemento 307 e exposição do canal pulpar (utilizou-se espelho para refração da imagem) conforme observado na Figura 5A.

A frequência cardíaca, frequência respiratória, grau de desidratação, tempo de preenchimento capilar e mucosas estavam dentro dos valores normais. O exame complementar realizado foi a radiografia de projeção latero-lateral e dorsoventral do crânio (Figura 2) e indicada a exodontia do $3^{\circ}$ pré-molar, pela técnica intra-oral.

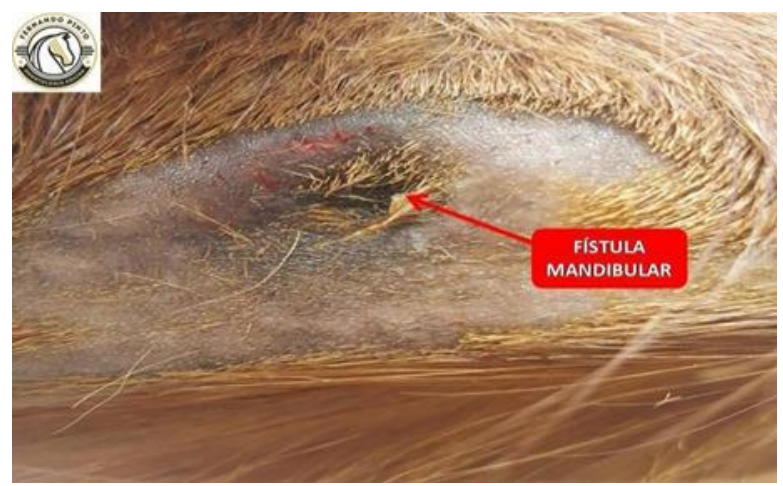

Figura 1. Fístula na região mandibular.

Foi estabelecido o procedimento cirúrgico para exodontia e correção das alterações dentárias tais como dos ganchos craniais, odontoplastia das pontas excessivas do esmalte dentário tanto da arcada superior como da arcada inferior (Figura 3). Ambas usando as canetas longas anguladas disco e vestibular.

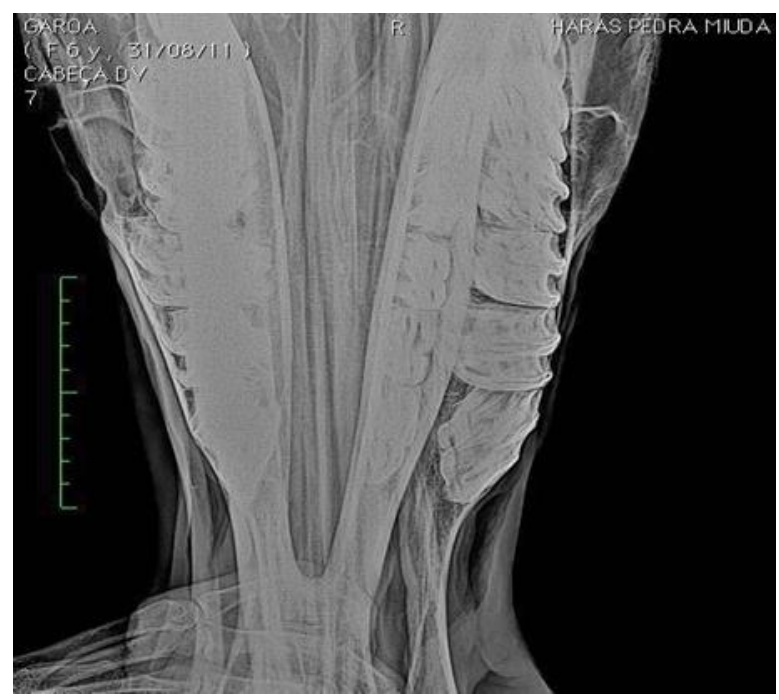

Figura 2. Radiografia cranial de uma égua, obtida pela projeção dorso-ventral por meio da técnica digital.

O animal foi submetido a sedação com detomidina a $1 \%$ administrado pela via intravenosa, e bupivacaína em anestesia local do nervo mandibular. Foi utilizada uma seringa de pressão para limpeza da cavidade oral com água (durante todo procedimento), antisséptico e espelhos para visualização do alvéolo dentário.

A exodontia do elemento dentário 307 pela técnica de extração intra-oral, removendo o elemento dentário pela cavidade oral, no qual foram utilizados os instrumentais cirúrgicos como 
afastador de vários tamanhos $(3,6,9 \mathrm{~cm}$ de acordo com o tamanho e espaço entre os dentes do animal), com função de romper os ligamentos periodontais (Figura 4). Foi usado boticão para retirada do dente, a curetagem no alvéolo para não deixar nenhum fragmento dentário e um plug para introduzir dentro do alvéolo do dente que foi extraído, dissolvendo a medicação metronidazol no plug como tratamento (Figura 5).
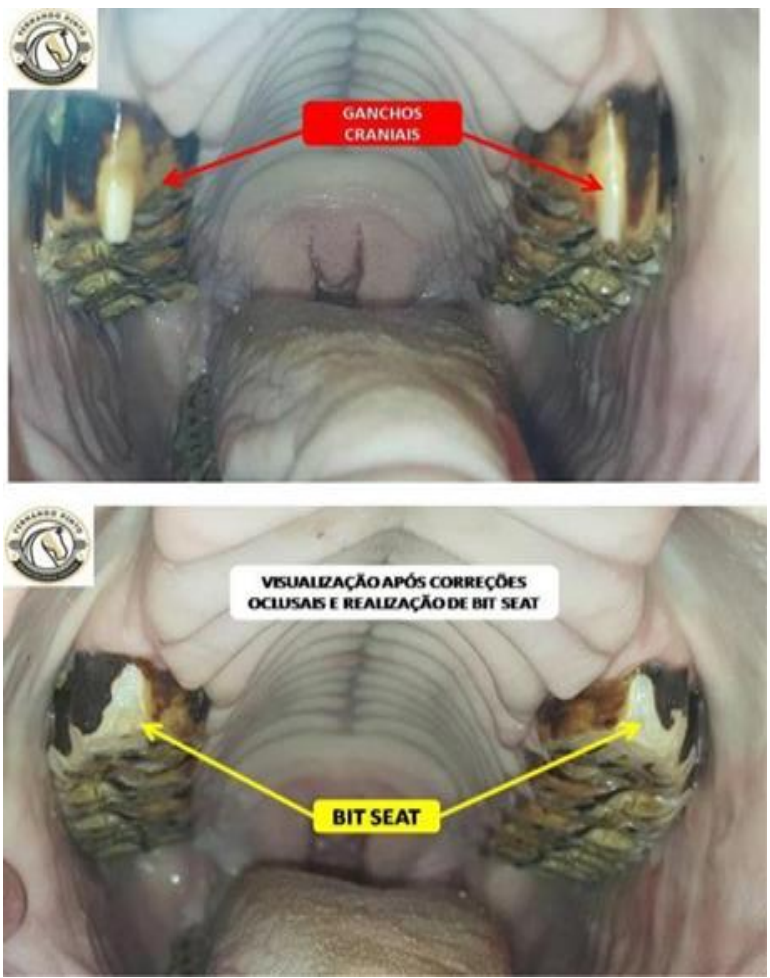

Figura 3. Correções oclusais.

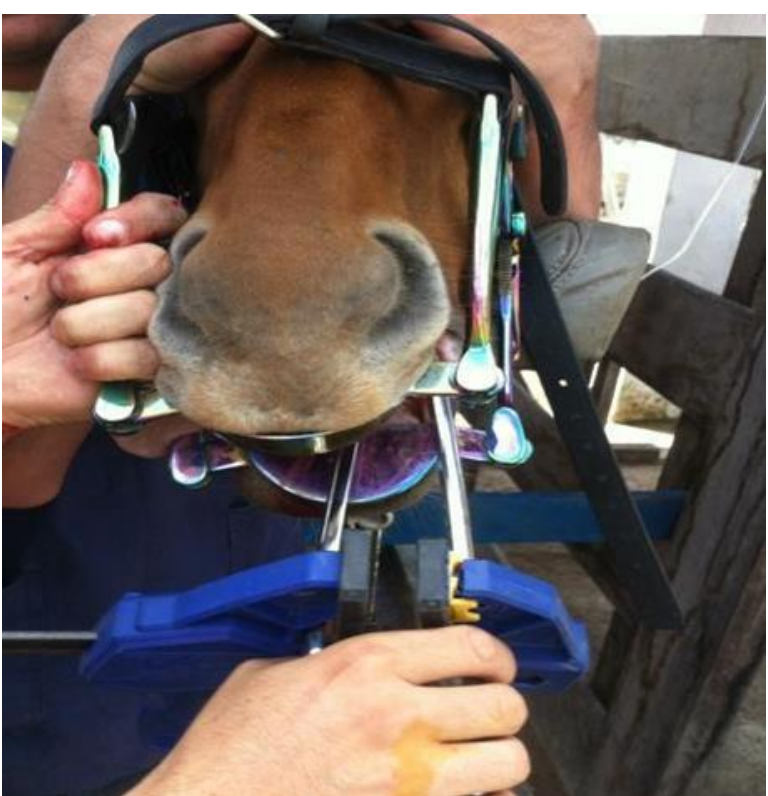

Figura 4. Afastador para rompimento dos ligamentos.

Para o tratamento pós-cirúrgico foi administrado por via intramuscular a medicação flunixin meglumine $(2,2 \mathrm{mg} / \mathrm{kg})$ S.I.D., I.V.; antibioticoterapia com penicilina S.I.D., I.M. e metronidazol dissolvido no plug dentro do alvéolo.

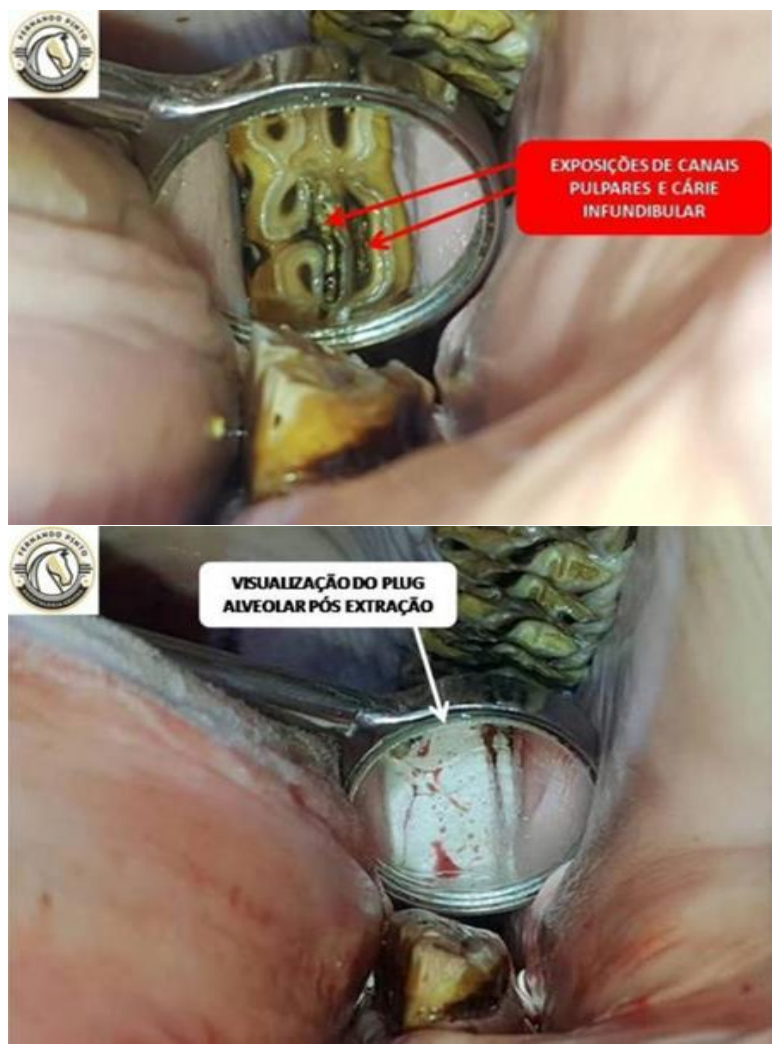

Figura 5. A. Exposição de canais pulpares e cáries infundibular. B. plug alveolar pós-extração dentária.

\section{Discussão}

$\mathrm{O}$ uso de sedativos e anestesias foram um avanço para a odontologia em equinos, facilitando os procedimentos de exodontia intra-orais. Como forma de administração para sedativos em infusão contínua, recomendando-se detomidina e xilazina, bem como as lidocaínas, bupivacaína, mepivacaína para anestesias locais (AlencarAraripe et al., 2013). As indicações para exodontia de pré-molares e molares são várias, à exemplo das cáries infundibulares, exposições de canais, dentre outras. Isto, caso o animal se encaixe nas patologias e alterações dentárias exemplificadas acima. Neste caso a técnica de exodontia intraoral foi a mais conivente por ser um procedimento prático, para retirar o elemento dentário pela cavidade oral, causando menos prejuízo comparado à outras técnicas.

Utilizando os instrumentais cirúrgicos corretos para tal técnica, riscos e prejuízos para o animal são baixos. Trabalhando-se com o afastador do tamanho apropriado para o equino, posicionado 
corretamente no elemento dentário, associado com movimentos laterais, tem por função romper os ligamentos periodontais, visualizando-se sangue espumoso ao arredor do dente (Dixon et al., 2006).

As complicações são poucas quando se tem um domínio da técnica e conhecimento anatômico, uma vez que o animal tinha problemas como uma fístula na região mandibular em consequência da infecção bacteriana no elemento dentário 307, expondo o canal que ligava a face externa com a cavidade oral. Pelas observações citadas e com base nos autores mencionados acima, obteve-se um resultado positivo dos procedimentos, com boa recuperação fisiológica e de atividade embrionária. As imagens radiográficas são de suma importância para obter a visualização dos elementos dentários e, programar o melhor tratamento (Escodro et al., 2013). Tal afirmação assemelha-se ao caso da égua que se encontrava na cidade de Gravatá-PE, relatado nesse trabalho.

\section{Conclusão}

As avaliações e manutenções odontológicas precisam ser intensificadas cada vez mais na rotina dos haras, principalmente em se tratando da boca e dentes, que por sua vez causam perdas econômicas e funcionais, quando não se têm essa prática, o procedimento de exodontia, ao decorrer do tempo tornou-se mais frequente como forma de tratamento na grande maioria dos atendimentos. $\mathrm{O}$ conhecimento perante as técnicas cirúrgicas e anestésicas é de suma importância para minimizar os problemas pós-cirúrgicos que possam ocorrer, alcançando assim a recuperação do animal e retorno das suas atividades em menor espaço de tempo. A técnica intra-oral supriu o tratamento e resolveu a patologia desse animal, esta apresenta vantagens, como por exemplo o fato de não ser necessário submeter o animal a uma anestesia geral, e não ser cruenta quando comparada a outras técnicas, como desvantagens pode ser citado que nem todos os casos de exodontia poderá ser solucionado por este método.

\section{Referências}

Alencar-Araripe, M. G., Costa, A. C. H., Costa, B. O., Castelo, D. d. S. C. M., \& Nunes-Pinheiro, D. C. S. (2013). Saúde bucal: conforto e rendimento ponderal em equinos póstratamento dentário. Revista Brasileira de Higiene e Sanidade Animal, 7(2), 288-300.

Dixon, P. M., \& Dacre, I. (2005). A review of equine dental disorders. The Veterinary Journal, 169(2), 165-187.

Dixon, P. M., Dacre, I., Kempson, S., \& Smith, L. (2006). Idiopathic cheek teeth fractures, including practice-based and hospital-based surveys. Paper presented at the Proceedings of the American Association of Equine Practitioners.

Easley, J., Dixon, P. M., \& Schumacher, J. (2010). Equine dentistry: Saunders.

Escodro, P. B., Mariz, T. M. A., Júnior, J. V. T. F., Fonseca, L. S., Bernardo, J. O., \& Oliveira, C. F. (2013). Trepanação óssea e extração de molares com equino em posição quadrupedal: Relato de caso. Acta Veterinaria Brasilica, 7(1), 76-80.

Kreling, K. (2003). Horses teeth and their problems. 2nd ed. Cadmos Horse Guides, 128p. (3th ed. Vol. 1): Cadmos Horse Guides.

Recebido: 31 Agosto ,2018.

Aprovado: 24 Setembro, 2018

Publicado: 20 Outubro, 2018

Licenciamento: Este artigo é publicado na modalidade Acesso Aberto sob a licença Creative Commons Atribuição 4.0 (CC-BY 4.0), a qual permite uso irrestrito, distribuição, reprodução em qualquer meio, desde que o autor e a fonte sejam devidamente creditados. 